
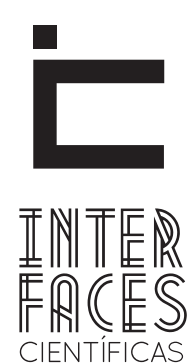

EDUCAÇÃO

ISSN IMPRESSO 2316-333X

E-ISSN 2316-3828

DOI-10.17564/2316-3828.2017v5n2p91-104

\title{
A IMPRENSA NO NORDESTE BRASILEIRO: CORRESPONDÊNCIAS SOBRE INSTRUÇ̃̃O PÚBLICA COMO FONTE E OBJETO DE PESQUISA
}

THE PRESS IN BRAZILIAN NORTHEAST: CORRESPONDENCE ON PUBLIC INSTRUCTION AS SOURCE AND RESEARCH PURPOSES LA PRENSA EN NORDESTE BRASILEÑO: CORRESPONDENCIA DE INSTRUCCIÓN PÚBLICA COMO FUENTE DE INVESTIGACIÓN Y PROPÓSITOS

Fabiana Sena ${ }^{1}$

Larisse Lima de Sousa ${ }^{3}$
Bianca Machado de Oliveira²

\section{RESUMO}

0 estudo busca dar visibilidade ao processo de catalogação das cartas sobre instrução pública nos jornais $O$ Araripe (1850-1860), O Cearence (1840-1899), Diário do Maranhão (1855-1858), Publicador Maranhense (18421886), Diário de Pernambuco (1825-1888) e Argos Pernambucano (1850-1852), Diário da Bahia (1833-1838) e Correio da Bahia (1871-1878). A escrita dessas cartas é ordinária de sujeitos que compuseram a instrução pública da época, professores, diretores da instrução pública e das escolas e de anônimos. A pesquisa permitiu catalogar esses escritos, servindo de fonte para pesquisas sobre Instrução e Império no Brasil. Neste trabalho, buscamos traçar os caminhos metodológicos utilizados, bem como as técnicas usadas para a execução da investigação. Os discursos apresentados, neste trabalho, demonstram que os signatários escreviam para o jornal para dar parecer, avisar, reclamar, pedir, noticiar, repreender... Com efeito, dar visibilidade a esses discursos sob a escrita epistolar é relevante por serem históricos e de serem de sujeitos que atuaram na instrução pública, já que a imprensa apresenta flagrantes sobre o cotidiano escolar de tempos passados, por meio de uma sociedade de correspondência que havia nesse suporte textual, veículo de comunicação mais comum do período. 


\section{PALAVRAS-CHAVE}

Cartas. Instrução Pública. Jornal. Século XIX.

\section{ABSTRACT}

The study seeks to give visibility to the process of cataloging the letters on public education in the newspapers O Araripe (1850-1860), O Cearence (1840-1899), Diário do Maranhão (1855-1858), Publicador Maranhense (1842-1886), Diário de Pernambuco (18251888) e Argos Pernambucano (1850-1852), Diário da Bahia (1833-1838) e Correio da Bahia (1871-1878). The writing of these letters is ordinary subjects who composed the public education of the time, teachers, directors of public education and schools and anonymous. The research allowed to catalog these writings, serving as a source for research on education and Empire in Brazil. In this work, we trace the methodological approaches used and the techniques used to carry out the investigation. The speeches presented in this paper show that the signatories wrote for the newspaper to give advice, warning, complain, ask, disclose, scolding... To give visibility to these speeches in the epistolary writing is relevant because they are historical and are of subjects who worked in public education, as the press has major on the school routine of past times, through a matching company that had this textual support, most common communication vehicle for the period.

\section{KEYWORDS}

Letters. Public Instruction. Newspaper. 19th Century.

\section{RESUMEN}

El estudio pretende dar visibilidad al proceso de catalogación de las cartas en la educación pública en los periódicos O Araripe (1850-1860), O Cearence (1840-1899), Diário do Maranhão (1855-1858), Publicador Maranhense (1842-1886), Diário de Pernambuco (1825-1888) e Argos Pernambucano (1850-1852), Diário da Bahia (1833-1838) e Correio da Bahia (18711878). La escritura de estas cartas es acerca de temas comunes y corrientes que componían la educación pública del período, los maestros, los directores de las escuelas y de la educación pública y anónima. La investigación permitió catalogar estos escritos, que sirven como fuente para la investigación sobre la educación y el Imperio de Brasil. En este trabajo, rastreamos los enfoques metodológicos utilizados y las técnicas utilizadas para llevar a cabo la investigación. Los discursos presentados en este documento muestran que los firmantes escribieron para el periódico para dar consejo, advertir, reclamar, preguntar, divulgar, reprender... Dar visibilidad a estos discursos en la escritura epistolar es relevante debido a que son históricos y son de sujetos que trabajaban en la educación pública, ya que la prensa tiene importante en la rutina de la escuela de los tiempos pasados, a través de una empresa de correspondencia que tenía este apoyo textual, vehículo de comunicación más común para el período. 


\section{PALABRAS CLAVE}

Cartas, Instrucción Pública, Periódico, Siglo XIX

\section{INTRODUÇ̄̃̃O}

Este trabalho tem como objetivo dar visibilidade às atividades de pesquisa desenvolvidas por um grupo de pesquisadores da Universidade Federal da Paraíba (UFPB), cujo interesse é apresentar fontes para a História da Educação na Paraíba e no Nordeste. 0 projeto Sociedade de correspondência e a instrução pública nos jornais do Nordeste no Império, financiado pelo Conselho Nacional de Desenvolvimento Científico e Tecnológico (CNPq), por meio do Edital Universal 2013, se insere nas ações do grupo de pesquisa Memória, História e Educação e do Núcleo de Estudos em Leitura e Escrita Michel de Certeau, ambos localizados na UFPB, e teve como integrantes estudantes da graduação de licenciatura - PIBIC e PIVIC.

A pesquisa buscou identificar, inventariar, classificar as cartas sobre instrução pública nos jornais $O$ Araripe (1850-1860), O Cearence (1840-1899), Diário do Maranhão (1855-1858), Publicador Maranhense (1842-1886), Diário de Pernambuco (1825-1888) e Argos Pernambucano (1850-1852), Diário da Bahia (1833-1838) e Correio da Bahia (1871-1878). Tais cartas foram escritas por sujeitos que compuseram a instrução pública da época, professores, diretores da instrução pública e das escolas e de anônimos. Por meio da tipologia das cartas nos jornais que se estabeleceu em pesquisas anteriores (SENA, 2012; 2014), foi possível verificar a posição dos leitores-escritores na ordem social no Império e como eles se mobilizaram em seu interior.

Assim, com escritos de reclamação, de pedidos, de ordem, de protestos e de agradecimentos, os pro- fessores e diretores marcaram os seus lugares sociais. Para tanto, apontamos aqui o lugar de onde partimos para realizar essa pesquisa e apresentar as nossas motivações. Buscamos, igualmente, traçar os caminhos metodológicos utilizados, bem como as técnicas usadas para a execução da investigação.

Verificar se esses modos de escritas desses leitores-escritores, professores e diretores da instrução pública, se encontravam nos jornais de outras províncias do Nordeste - Bahia, Ceará, Maranhão e Pernambuco - no período imperial foi a motivação para realizar essa investigação, a qual permitiu catalogar esses escritos, servindo de fonte para pesquisas sobre Instrução e Império no Brasil. As questões que direcionaram as atividades de catalogação foram: Os professores e diretores da instrução pública escreviam nos jornais de maior circulação no Ceará, Pernambuco, Bahia e Maranhão? Se sim, quais as reivindicações, os pedidos, as ordens ou comunicados que esses signatários faziam por meio da escrita epistolar nos jornais? Havia outros os signatários? Quem eram os destinatários dos discursos sobre a instrução pública nos jornais? Quais são as estratégias discursivas que os autores das cartas utilizaram para transmitir o conteúdo? Qual o modelo de composição epistolar que os signatários se apropriaram para transmitir o conteúdo da carta?

A escolha dos jornais das províncias da Bahia, Ceará, Maranhão e Pernambuco se deu em razão de estarem disponibilizados on-line com maior circulação no site da Biblioteca Nacional do Rio de Janeiro 
(Hemeroteca Digital), exceto o Diário de Pernambuco, o qual se encontra no site da University of Florida Digital Collections. Este por ser diário desde o seu surgimento apresenta ampla circulação da província de Pernambuco, sendo, assim, eleito para a pesquisa. A restrição por quatro províncias foi em razão do tempo de execução da pesquisa e por muitos periódicos escolhidos serem diários, apresentando um volume imenso de informações para identificar e catalogar. Quanto aos jornais da província da Paraíba, a identificação e catalogação das epístolas foram realizadas no período de 2010 a 2012, em decorrência da pesquisa desenvolvida com financiamento do $\mathrm{CNPq}$, por meio do Edital Universal 2010.

Os periódicos tratados aqui não são especializados em educação e/ou ensino, entretanto estes registram fragmentos do cotidiano escolar, os quais nos possibilitam compreender determinados aspectos da instrução pública no Império, pois não foram “[...] lidos ingenuamente como uma informação direta e/ou neutra, de conteúdo denotativo e referencial simples [...]", conforme Pécora (2005, p. 12) quando anuncia que os documentos epistolares são comumente tratados.

Esses periódicos foram tratados como fonte para a identificação e catalogação das epístolas que tratam da instrução pública, considerando-as em suas especificidades e situando-as em suas condições de produção e circulação, tendo em vista que "a palavra constitui o meio privilegiado de acesso a atitudes e representações do sujeito" (MALATIAN, 2009, p. 196). Nessa perspectiva, esse tratamento auxilia na ampliação da compreensão sobre a instrução pública no Império, uma vez que cresce estudos, tomando os discursos produzidos na imprensa como fonte de pesquisa.

Ao tomar como fonte o jornal, foram consideradas as orientações de Barbosa (2007) a respeito de utilizá- los como fonte primária. Segundo a autora, os textos presentes nos periódicos apresentam uma linguagem alegórica, de modo que verificamos em que medida aquele texto, aparentemente sem sentido, guardou em si uma relação "secreta" com alguma notícia dada no mesmo jornal. A partir desse ponto de vista, consideramos também que o conteúdo no jornal não se constitui em um objeto único e isolado.

Dito de outro modo, o conteúdo em si não podia ser dissociado do lugar ocupado pela publicação, já que "a imprensa periódica seleciona, ordena, estrutura e narra, de uma determinada forma, aquilo que se elegeu como digno de chegar até o público" (BARBOSA, 2007, p. 30). Nesse sentido, foram consideradas "as diferenças na apresentação física e estruturação do conteúdo [que] não se esgotam em si mesmas, antes apontam para outras, relacionadas aos sentidos assumidos pelos periódicos no momento da sua circulação" (LUCA, 2010, p. 132).

O jornal do século XIX se constitui em elementos variados, tornando-se "indisciplinado", se compararmos aos jornais da atualidade, conforme Barbosa (2007). Fez-se necessário, também, considerar esse suporte, onde as cartas foram publicadas, como uma representação da escrita de um tempo e não como "um espelho fiel da realidade" (MOREL, 2010, p. 8). 0 olhar atento sobre a imprensa permite verificar as diversas vozes propaladas nele bem como diferentes escritos que se fazem presentes, assinados ou não.

O estudo nos e pelos periódicos possibilita reconhecer “[...] que o século XIX não é fácil de ser compreendido, pois ao mesmo tempo próximo e distante de nós, gerou instituições, vocabulários e valores que, semelhantes aos atuais, são também bastante diferentes" (MOREL, 2010, p. 9). Assim, a imprensa nesse período, e em qualquer outro, deve ser considerada como o lugar da recepção e difusão dos discursos múltiplos, onde e quando os debates culturais, políticos e literários se criavam e/ou se firmavam por meio da escrita.

Após a identificação do corpus nos jornais, passamos para a segunda fase da pesquisa quando utilizamos como fonte os manuais de escrever cartas, a exemplo de Corte na aldeia (1618), de Francisco 
Rodrigues Lobo; La Secretaire à laMode (1650), de Sieur de la Serre; Le Nouveau Secretaire de La Cour (1714) de Monsieur Milleran, O secretário português ou o método de escrever cartas (1801) de Francisco José Freire (Cândido Lusitano), Manual delescribiente (1831) de Romualdo Paronce e o capítulo destinado à escrita epistolar em O Código do bom-tom (1845) de José Inácio Roquette, Novo Secretário Português ou Código Epistolar (1860, $3^{\mathrm{a}} \mathrm{ed}$.) J. I Roquette os quais se encontram disponíveis na internet, a fim de verificarmos a maneira de conceber e organizar a escrita epistolar, bem como apontar a relação que se estabelece entre esses manuais e o corpus, já que o dito também está revelado nas regras da comunicação epistolar.

De acordo com Rocha (1965, p. 30) houve um desejo de consagrar o gênero por meio de "formulários teóricos ou antológicos [que] fixam as regras de composição ou arrolam padrões apropriados às diversas circunstâncias da vida privada e social”. Esses manuais foram localizados na internet a partir das indicações nos trabalhos de Chartier (1991), Dauphin (1991), Castillo Gómez (2002), Sierra Blas (2003), Bastos (2004) e Barbosa (2011), os quais integram a literatura de civilidade, pois, o domínio da arte epistolar também torna o sujeito cortês, polido e civilizado. Nessa perspectiva, Castillo Gómez (2002b, p. 15) afirma que "al escribir una carta, quien lo hace participa, conscientemente o no, de una tradición asentada en el curso de los siglos, de un modo de hacer inveterado".

Ao considerar que fontes "são vestígios, testemunhos" e que são "uma construção do pesquisador, isto é, um reconhecimento que se constitui em uma denominação e em uma atribuição de sentido; é uma parte da operação historiográfica" (RAGAZZINI, 2001, p. 14), essa pesquisa sobre a produção de fontes no âmbito da História da Educação é um trabalho complexo, em razão do desconhecimento de que as cartas podem ser tratadas no âmbito público, resultando somente de "atividades solitárias de introspecção, ainda que sua autoria possa ser partilhada por secretários, assessores ou familiares" (MALATIAN, 2009, p. 195).
Assim, faz-se necessário tornar visível o discurso epistolar sobre a instrução pública no Império entre as províncias do Nordeste, de modo que propomos aqui organizar e estruturar uma fonte histórica, por criar novas formas de compreender esse gênero, dando a conhecer a forma e o conteúdo como este tem se apresentado no século XIX por meio da imprensa.

\section{NO RASTRO DAS CARTAS SOBRE INSTRUÇÃO PÚBLICANOS JORNAISDONORDESTE BRASILEIRO DO SÉCULO XIX}

A pesquisa nos jornais do Nordeste brasileiro do século XIX inventariou 1231 escritos de professores, diretores, inspetores e outros sujeitos que compuseram a instrução pública da época. 0 corpus resultante dessa pesquisa está disponibilizado no site Jornais e Folhetins da Paraíba do século XIX (http://www.cchla. ufpb.br/jornaisefolhetins/index.html), cujo espaço abriga pesquisas de professores da UFPB sobre o século XIX na Paraíba.

Ao seguir as orientações de pesquisa no jornal, conforme apresentado no tópico anterior, verificamos que as cartas, costumeiramente, não eram publicadas em seção específica, podendo estar presente em qualquer parte do jornal. Para localizar esse tipo de gênero discursivo, foi preciso constatar que a carta no jornal não exibia a mesma estrutura das cartas privadas: data, saudação, conteúdo, despedida e assinatura. Em razão disso, adotamos o 'paradigma indiciário' (GINZBURG, 1989) para a identificação das epístolas nos jornais, de modo a atentar para os detalhes, pistas ou indícios, pois, "se a realidade é opaca, existem zonas privilegiadas - sinais, indícios - que permitem decifrá-la” (GINZBURG, 1989, p. 177).

Ao lermos os jornais, preocupamo-nos em observar as repetições de assuntos, discursos, os destinatários, os signatários, para as informações cruzadas, 
ou seja, dados que remetem para cartas anteriores ou anunciam as posteriores, como, por exemplo, 'esperamos respostas'. No que tange aos destinatários, atentamos para as seguintes expressões: 'ao inspetor da instrução', 'ao diretor da instrução', 'ao delegado da instrução' e 'ao professor'. Já os signatários, a nossa atenção foi para os pseudônimos ou para o teor da epístola. A ausência de assinatura nas cartas publicadas nos jornais revela o cuidado que o leitor-escritor precisava ter para não sofrer represálias de outros leitores ou dos destinatários, bem como poderia se configurar como um meio dos editores/redatores aceitarem os seus escritos para serem publicados.

Os leitores-escritores escreviam para o jornal com o objetivo de reclamar, pedir, ordenar ou requerer. Isso nos permitiu atentar igualmente para os verbos, os quais serviram de indícios para a classificação dos discursos, a saber: ordenar, mandar, remeter, pedir, verificar, cumprir e responder. Esses marcadores discursivos, nas variadas conjugações, possibilitaram classificar o conteúdo das cartas, bem como identificar os possíveis signatários e destinatários, pois, muitas das cartas não eram assinadas e/ou endereçadas explicitamente.

As transcrições foram realizadas, mantendo as paragrafações, grifos em negrito ou itálico, as notações numéricas, as pontuações e a ortografia. Consideramos relevante a permanência da estrutura sintática do discurso, por entendermos que "uma mesma palavra pode conter matizes e significados distintos, dependendo se ela está só ou acompanhada de outros vocábulos” (MELO, 2010, p. 20). A nossa compreensão para preservar a escrita original é em razão do texto tão-somente ser entendido quando se conhece o seu contexto e a sua materialidade.

Nesse sentido, adaptamos o quadro elaborado por Aldrigue e Nicolau (2009) - conforme Quadro 1 e, quando se fez necessário, durante as transcrições, utilizamos as palavras "ilegível" ou "corroído" entre colchetes. A utilização da padronização explicitada no Quadro a seguir foi necessária para deixar claro que no recorte havia uma limitação devido à conservação do jornal.

Quadro 1 - Legenda referente às expressões utilizadas nas transcrições

\begin{tabular}{|c|l|l|}
\hline EXPRESSÃO & OCORRÊNCIA & \multicolumn{1}{c|}{ EXEMPLO } \\
\hline [ilegível] & \multirow{2}{*}{$\begin{array}{l}\text { Indica que uma } \\
\text { dessas situações } \\
\text { aconteceu no } \\
\text { [corroído] }\end{array}$} & $\begin{array}{l}\text { Assimodo de } \\
\text { texto transcrito. } \\
\text { tempol] que há } \\
\text { tempos. }\end{array}$ \\
$\begin{array}{ll}\text { vende-se huma } \\
\text { propriedade } \\
\text { [corroído] de três } \\
\text { andares. }\end{array}$ \\
\hline
\end{tabular}

Fonte: Adaptado de Aldrigue e Nicolau (2009).

O processo de classificação das epístolas sobre instrução pública foi realizada conforme o Quadro 3 de tipologia de cartas. A exemplo disso, o Quadro 2, abaixo, exibe transcrições de cartas e suas respectivas classificações. Faz-se necessário ressaltar que, muitas vezes, os discursos identificados apresentam duplicidade de classificação. Há discursos que sua classificação não está de acordo com os manuais, já que esse material tem suas limitações de gêneros discursivos. 
Quadro 2 - Classificações de cartas

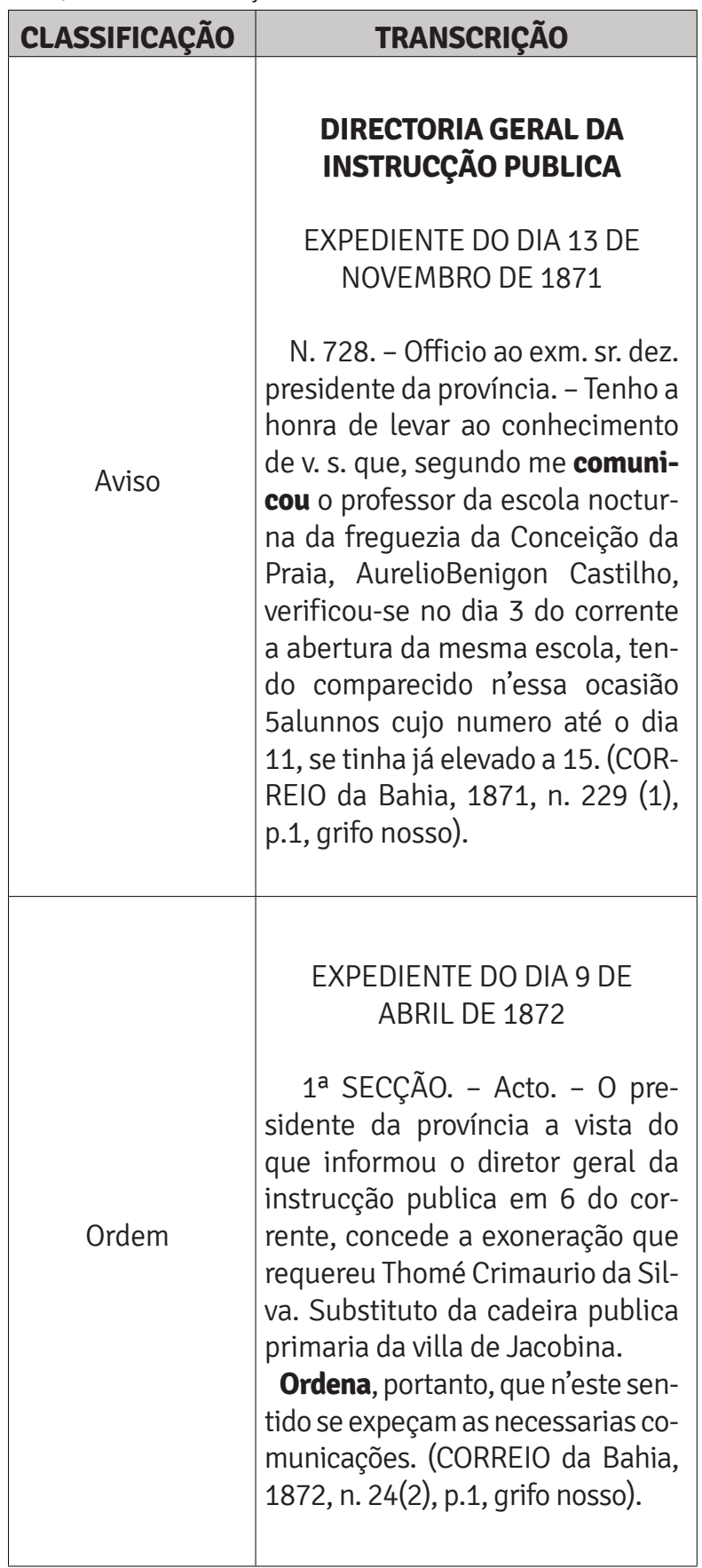

\begin{tabular}{|c|c|}
\hline CLASSIFICAÇÃO & TRANSCRIÇÃO \\
\hline Parecer & $\begin{array}{l}\text { N. 4852. - Bemvindo Alves } \\
\text { Barbosa, professor da cadeira } \\
\text { publica primaria da casa de pri- } \\
\text { são com trabalho; pedindo ser } \\
\text { considerada a referida cadeira } \\
\text { em } 3^{a} \text { classe. - Não tem logaro } \\
\text { que requer o supplicante, visto } \\
\text { como dá aula uma só vez por dia } \\
\text { e não paga aluguel de casa para } \\
\text { ella. (CORREIO da Bahia, 1873, } \\
\text { n. } 242(2), \text { p.2, grifo nosso). }\end{array}$ \\
\hline Ordem & 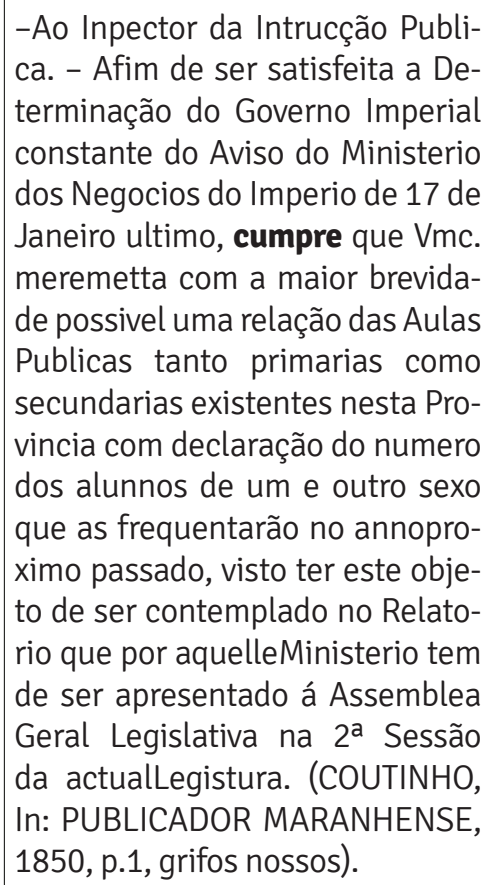 \\
\hline Petição & $\begin{array}{l}\text { Ao diretor da instrucção publica } \\
\text { da província para propor pessoa } \\
\text { habilitada a fim de reger a aula do } \\
\text { ensino mutuo da capital durante o } \\
\text { impedimento do professor respec- } \\
\text { tivo. (O CEARENSE, 1855. p.01, } \\
\text { grifos nossos). }\end{array}$ \\
\hline
\end{tabular}




\begin{tabular}{|c|c|}
\hline CLASSIFICAÇÃO & TRANSCRIÇÃO \\
\hline Repreensão & $\begin{array}{l}\text { Illm } \text { Senhor Montisuma } \\
\text { Agoa e conselho, diz o rifão, só se } \\
\text { dá a quem pede; maz nem por isto } \\
\text { deixa de ser huma obra meritória } \\
\text { dar bons conselhos. Não he pru- } \\
\text { dente, não he mesmo legal, que V. } \\
\text { m. abandone sua aula dias e dias } \\
\text { para andar mascateando fazendas } \\
\text { pelas feiras de Porteiras e Jardim. } \\
\text { Assim obrando, em prejuiso de } \\
\text { sua reputação de assiduo, V. m. } \\
\text { ainda se faz outro mal, que vem } \\
\text { a ser, degradar-se hum pouco da } \\
\text { attitude grave e respeitosa, que } \\
\text { deve manter, como empregado da } \\
\text { instrução, gente, que urge ser mui } \\
\text { circunspecta. Está bem visto que } \\
\text { o povo consagra pouco respeito } \\
\text { ahuma pessoa, que sentado debai- } \\
\text { xo de huma latada com huma mala } \\
\text { de fazendas entre as pernas e de } \\
\text { todos os lados cercado de gentes } \\
\text { grosseiras e abjectas, pôr-se a gri- } \\
\text { tar em pleno auditório: = Cheguem } \\
\text { fregueses, ajudem seopae, que he } \\
\text { velho! ... Acho que este papel não } \\
\text { lhe assenta; a hum rapaz ficaria } \\
\text { milhor Desejo-lhe saude. Até a fei- } \\
\text { ra. Seo patrício e amigo, O TRON- } \\
\text { XO. (O TRONXO, In: O ARARIPE, } \\
\text { 1856, p. 4, grifos nossos). }\end{array}$ \\
\hline
\end{tabular}

Fonte: Dados da pesquisa (2016).

No primeiro exemplo, frases como "[...] levar ao conhecimento de v. s. que, segundo me comunicou [...]" nos levaram a classificá-la como carta de aviso. Nessa perspectiva, Freire (1801, p. 183) afirma que "as cartas de aviso forão as primeiras que usam os primeiros escritores, por que não se inventarão composições epistolares para outro fim, mas para avisar amigos ausentes de cousas, que ou a eles ou a nós pertence”.
No segundo, a palavra "ordena" suscitou a classificação como carta de ordem. Embora os manuais não definissem essa classificação, inserimos em razão das cartas apresentarem verbos que determinam essa configuração, a de ordem. De acordo com Sena (2014a, p. 90), “Estas cartas podem se configurar como aviso, uma espécie de comunicação, notícia curta comparada às demais cartas [...]. Por meio dessas mensagens, os signatários designam aos seus subordinados as suas atividades [...]".

Quanto ao terceiro exemplo, ainda que apresente a descrição de uma petição, ao final do discurso é dado um parecer, negando a solicitação do requerente. $\mathrm{Na}$ perspectiva, do manual de escrever carta, Roquette (1860, p. 52) define esta classificação como sendo “motivadas d'outras em que se consulta alguém, se Ihe pede o seu parecer, o auxílio das suas luzes, a solução d'alguma dificuldade, etc."

Os gêneros das cartas estão fundados na tradição da retórica, qual seja, a teoria e prática da argumentação persuasiva, conforme Aristóteles (2005). Este filósofo defende, na Retórica, a ideia de que o discurso de uma pessoa busca o convencimento com a palavra, pois todas as pessoas "tentam em certa medida questionar e sustentar um argumento, defender-se ou acusar" (ARISTÓTELES, 2005, p. 89), e, para se alcançar tal propósito, é preciso usar o logos (junção de costume e caráter de quem fala). Este amálgama do ato de discursar não pode ser desprezado, pois isso dá credibilidade.

Segundo Aristóteles (2005, p. 89), “todas as pessoas de alguma maneira participam [da retórica], pois todas elas tentam em certa medida questionar e sustentar um argumento, defender-se ou acusar". A importância de expor o aporte retórico da epístola demonstra que para cada tipo há uma forma de discurso apropriada, e que, de acordo com Aristóteles, todo discurso é composto de três elementos, como o orador (signatário), o assunto de que fala (mensagem) e o ouvinte (destinatário). 
As cartas encontradas nos jornais do Nordeste foram inseridas em fichas criadas para esse fim. Em termos estruturais, formulamos um quadro em que consta o nome do jornal e a sua data de publicação; signatário e destinatário da carta e sua classificação; e recorte do jornal e sua transcrição, conforme exemplificamos abaixo.

Quadro 4 - Cartas coletadas no jornal Diário da Bahia (1833-1838)

\begin{tabular}{|c|c|}
\hline \multicolumn{2}{|c|}{ DIÁRIO DA BAHIA - 1837} \\
\hline & $\begin{array}{l}\text { Assunto: oferta de vagas em hospital } \\
\text { particular }\end{array}$ \\
\hline $\begin{array}{l}\text { Jornal: } \\
\text { Diário da Bahia } \\
\text { Data: } \\
9 \text { de novembro } \\
\text { de } 1837 \\
\text { Signatário: } \\
\text { Hospital } \\
\text { Particular dos } \\
\text { Barriz. } \\
\text { Destinatário: } \\
\text { Leitores que } \\
\text { necessitam de } \\
\text { atendimento } \\
\text { médico } \\
\text { Classificação: } \\
\text { Notícia }\end{array}$ & $\begin{array}{l}\text { HOSPITAL PARTICULAR DOS BARRIZ. } \\
\text { Continua-se á receber no Hospital } \\
\text { supra-mencionado doentes de ambos } \\
\text { os sexos, pela diaria de } 2 \mathbb{W} \text { por cada } \\
\text { pessoa, e } 1 \mathbb{C} \text { por cada escravo. } \\
\text { Há quartos separados para doentes } \\
\text { do sexo feminino. } \\
\text { Os Professores abaixo assignados, } \\
\text { Directores do Hospital, fazem, como } \\
\text { de costume, conferencias trez vezes } \\
\text { na semana. } \\
\text { Jonathas Abbot, Lente de Anatomia } \\
\text { na Escola de Medicina. } \\
\text { Cezar Persiani, Ex } 1 .^{\circ} \text { Medico do } \\
\text { Hospitalde Lago. } \\
\text { Roberto Dundás, Medico-Cirurgião } \\
\text { do Hospital Britanico nesta Cidade. }\end{array}$ \\
\hline & Assunto: divulgação de cartas e livros \\
\hline $\begin{array}{l}\text { Jornal: } \\
\text { Diário da Bahia } \\
\text { Data: } \\
9 \text { de novembro } \\
\text { de } 1837 \\
\text { Signatário: } \\
\text { Comerciante } \\
\text { Destinatário: } \\
\text { Leitores } \\
\text { Classificação: } \\
\text { Negócios e } \\
\text { Encargos }\end{array}$ & $\begin{array}{l}\text { - Na casa de Livros n. }{ }^{0} \text { 410, no fim } \\
\text { da ladeira do Taboão, tem para ven- } \\
\text { der Cartas de Enterro de differentes } \\
\text { padrões, em papel de peso, á } 20 \text { rs. } \\
\text { cada uma, novas collecções de tras- } \\
\text { lados para lição da mocidade Brasi- } \\
\text { leira, Cartas de ABC, Arithmeticas, } \\
\text { Orthographias, GrammaticasPortu- } \\
\text { guezas, pelo Professor Casimiro, e } \\
\text { Livros em branco. }\end{array}$ \\
\hline
\end{tabular}

\begin{tabular}{|c|c|}
\hline \multicolumn{2}{|c|}{ DIÁRIO DA BAHIA - 1838} \\
\hline & $\begin{array}{l}\text { Assunto: solicitação para nomear pes- } \\
\text { soa de confiança da professora para } \\
\text { receber chave de sua propriedade }\end{array}$ \\
\hline $\begin{array}{l}\text { Jornal: } \\
\text { Diário da Bahia } \\
\text { Data: } \\
3 \text { de janeiro de } \\
1838 \\
\text { Signatário: } \\
\text { José Maria das } \\
\text { Neves e Almei- } \\
\text { da Varella } \\
\text { Destinatário: } \\
\text { D. Angelica, } \\
\text { professora } \\
\text { particular de } \\
\text { meninas } \\
\text { Classificação: } \\
\text { Aviso }\end{array}$ & $\begin{array}{l}\text { - A Senhora D Angelica, Professora } \\
\text { particular de Meninas, à rua de Baixo, } \\
\text { tenha a bondade de nomear pessoa } \\
\text { de sua confiança, para receber a } \\
\text { chave de sua propriedade, que o } \\
\text { abaixo assignado tem occupado, na } \\
\text { certeza de que, não o fazendo, desde } \\
\text { já declara, e protesta o annunciante- } \\
\text { naõ continuar a responsabilisar-se } \\
\text { pelos respectivos alugares. Bahia } 2 \\
\text { de Janeiro de } 1838 \text {. - José Maria das } \\
\text { Neves e Almeida Varella. }\end{array}$ \\
\hline
\end{tabular}

Fonte: Dados da pesquisa (2016).

Os discursos apresentados neste trabalho demonstram que os signatários - professores, diretores, membros da instrução pública ou outros sujeitos escreviam para o jornal para dar parecer, avisar, reclamar, pedir, noticiar, repreender, vender... Com essa manifestação de escrita, a epistolar, os escreventes teceram suas redes de comunicação, onde [...] "a demarcação do lugar, muitas vezes o destinatário e o remetente das epístolas são identificados, por compreender que é um discurso encaminhado para um determinado leitor, o que o constitui como seu principal valor distintivo" (SENA, 2014b, p. 269). A identificação da posição de cada escrevente sobre a instrução pública nos fornece pistas da sua organização e constituição na sociedade do Nordeste imperial.

Portanto, dar visibilidade a esses discursos sob a escrita epistolar é relevante por serem históricos e de 
serem de sujeitos que atuaram na instrução pública, já que a imprensa apresenta flagrantes sobre o cotidiano escolar de tempos passados, por meio de uma sociedade de correspondência que havia nesse suporte textual, veículo de comunicação mais comum do período.

\section{CONSIDERAÇÕES FINAIS}

O propósito de catalogar as cartas sobre instrução pública nos jornais do Nordeste brasileiro do século XIX e apresentá-las como fontes históricas da educação é tornar visível um gênero discursivo ainda pouco explorado no campo da historiografia da educação brasileira, em razão do desconhecimento de que as cartas podem ser tratadas no âmbito público, resultando somente de "atividades solitárias de introspecção, ainda que sua autoria possa ser partilhada por secretários, assessores ou familiares" (MALATIAN, 2009, p. 195).

A partir de Carr (2002), compreendendo o papel do historiador, como um selecionador, colocamo-nos a selecionar, classificar, sistematizar o discurso epistolar nos jornais para que pesquisadores reconheçam “[...] a origem e o momento histórico em que a fonte foi produzida, o alcance e o valor que se the pode atribuir, para que situação e em que circunstâncias ela foi produzida" (MELO, 2010, p. 20). Apresentar o processo pelo qual se constituiu a catalogação das cartas nos jornais do Nordeste brasileiro no Império traz à tona como o historiador aborda os fatos do passado, por meio do tratamento das fontes, que, de acordo com Carr (2002, p. 71), "[...] a história como um processo de interação, um diálogo entre o historiador localizado no presente e os fatos do passado".

A realização de pesquisas sobre o gênero epistolar no âmbito da História da Educação nos permitiu criar novas formas de compreender esse gênero, dando a conhecer a forma e o conteúdo como este tem se apresentado por meio dos manuais de escrever car- tas da França, Espanha e Portugal, no período entre o século XVI ao século XIX. Igualmente esta pesquisa evidenciou como esse gênero circulou nos jornais das províncias do Nordeste no século XIX, noticiando sobre a instrução pública - sujeitos, instituições, práticas pedagógicas e atividades burocráticas.

Assim, esse material ora apresentado possibilita justapor fontes, cruzar informações e cotejar documentos para a realização de outras pesquisas. Por meio dessa catalogação de fontes nos permite, ainda, levantar indícios de uma sociedade de correspondência, a partir dos testemunhos dos signatários e do (os/ as) destinatário (os/as) para a organização da cultura escolar, as formulações pedagógicas, instituições educacionais, sujeitos da educação e modos de escolarizar saberes no Império das províncias do Nordeste.

\section{REFERÊNCIAS}

\section{ALBUQUERQUE JÚNIOR, Durval M. A invenção} do Nordeste e outras artes. 4.ed. rev. São Paulo: Cortez, 2009.

ALDRIGUE, Ana Cristina de Sousa; NICOLAU, Roseane Batista. Quem pretende comprar dirija-se a...

Coletânea de anúncios paraibanos do século XIX. João Pessoa: Universidade Federal da Paraíba, 2009.

ARISTÓTELES. Retórica. 2.ed. Imprensa Nacional Casa da Moeda, 2005.

BARBOSA, Socorro de Fátima P. Jornal e literatura: a imprensa brasileira no século XIX. Porto Alegre: Nova Prova, 2007.

BARBOSA, Socorro de Fátima P. Códigos, regras e ornamentos nos secretários, manuais e métodos de escrever cartas: a tradição luso-brasileira. Veredas: Revista da Associação Internacional de Lusitanistas. Santiago de Compostela. V.15, junho 2011. 
CARR, Edward Hallet. Que é história? 8.ed. São Paulo: Paz e Terra, 2002.

CASTILLO GOMÉZ, Antonio. Como o polvo e o camaleão se transformam: modelos e práticas epistolares na Espanha moderna. In: BASTOS, Maria Helena Câmara et al (Org.). Destinos das letras. História, educação e escrita epistolar. Passo Fundo: UPF, 2002.

CHARTIER, Roger. Des 'secrétaires' pourlepeuple? Les modèlesé pistolaires de l'Ancien Régime entre litérature de cour et livre de colportage. In: CHARTIER, Roger (Dir.). La correspondance. Les usages de la lettreau XIX esiècle. Paris: Fayard, 1991.

DAUPHIN, Cécile Les manuelsépistolaires au XIXe siècle. In: CHARTIER, Roger (Dir.).

La correspondance. Les usages de la lettreauXIXesiècle. Paris: Fayard, 1991.

FREIRE, Francisco José. Secretário portuguez ou methodo de escrever cartas. Lisboa: Typografia Rollandiana, 1801.

GINZBURG, Carlo. Sinais, raízes de um paradigma indiciário. In: GINZBURG, Carlo. Mitos, emblemas, sinais: morfologia e história. São Paulo: Companhia das Letras, 1989. p.143-180.

LUCA, Tania Regina de. História dos, nos e por meio dos periódicos. In: PINSKY, Carla B. (Org.). Fontes históricas. 2.ed. São Paulo: Contexto, 2010.

MALATIAN, Teresa. Cartas: narrador, registro e arquivo. In: PINSKY, Carla B.; LUCA, Tânia Regina de. $\mathbf{O}$ historiador e suas fontes. São Paulo: Contexto, 2009.

MELO, José Joaquim Pereira. Fontes e métodos: sua importância na descoberta das heranças educacionais. In: COSTA, Célio Juvenal; MELO, Joaquim José Pereira; FABIANO, Luiz Hermenegildo (Org.). Fontes e métodos em história da educação. Dourados-MS: UFGD, 2010.
MOREL, Marco. Prefácio. In: BARBOSA, Marialva. História cultural da imprensa: Brasil - 1800-1900. Rio de Janeiro: Mauad X, 2010.

PÉCORA, Alcir. Velhos textos, crítica viva. In: TIN, Emerson (Org.). Arte de escrever: Anônimo de Bolonha, Erasmo de Rotterdam e Justo Lípsio. Campinas-SP: Unicamp, 2005.

RAGAZZINI, Dario. Para quem e o que testemunham as fontes da História da Educação? Educar, n.18, Curitiba: UFPR, 2001. p.13-28.

ROCHA, Andrée. A epistolografia em Portugal. 2.ed. Imprensa Nacional - Casa da Moeda, 1965.

ROQUETTE, José Ignácio. Novo secretário português ou código epistolar. 3.ed. J-P- Aillaud, Monlon, $C^{a}$. Paris. 1860 [1846].

SENA, Fabiana. As cartas sobre a instrução pública nos jornais paraibanos do Império. In: PINHEIRO, Antonio Carlos Ferreira; CURY, Cláudia Engler (Org.). Histórias da educação da Paraíba: rememorar e comemorar. João Pessoa: Universitária UFPB, 2012.

SENA, Fabiana. Imprensa e instrução pública no Império: o modo epistolar nos jornais do Rio de Janeiro e da Paraíba. Revista Brasileira de História da Educação. Maringá-PR, n.1, 2014. p.73-97.

SENA, Fabiana. “Ao diretor do lyceu”: cartas no jornal sobre o ensino secundário paraibano. Cadernos de História da Educação - v.13, n.1, janjun. 2014. p.267-283.

\section{SIERRA BLAS, Verónica. Aprender a escribir}

cartas. Los manuales epistolares en La Espana contemporânea. (1927-1945). Gijón/Astrias: Trea, 2003. 
Recebido em: 5 de novembro de 2016 Avaliado em: 14 de novembro de 2016 Aceito em: 12 de dezembro de 2016
1. Pós-doutora em Educação; Doutora em Letras; Professora Adjunta na Universidade Federal da Paraíba; Programa de Pós-Graduação em Educação da UFPB. E-mail: fabianasena@yahoo.com.br

2. Universidade Federal da Paraíba. E-mail: bianca.jpa@hotmail.com

3. Universidade Federal da Paraíba. E-mail: larisse.psicodesign@gmail.com 



\section{PRODUCÃÃO}

Editora Universitária Tiradentes

\section{IMPRESSÃO}

\section{Gráfica Gutemberg}

Universidade Tiradentes

\section{TIRAGEM}

200

\section{TIPOGRAFIA}

Signika

Bebas Neue

Arial

PAPEL

\section{Capa}

Papel Supremo 250g/m2

Miolo

Papel Offset 90g/m2 